\title{
Dinâmica recente da inflação brasileira em ambientes distintos de expectativas forward-looking
}

\author{
Recent dynamics of Brazilian inflation in different \\ environments of forward-looking expectations
}

ELANO FERREIRA ARRUDA

MARIA THALITA ARRUDA OLIVEIRA IVAN CASTELAR *

\begin{abstract}
RESUMO: Este estudo analisa como a inflação brasileira recente responde aos ciclos econômicos e ao seu componente inercial considerando ambientes distintos de expectativas forward-looking no arcabouço da Curva de Phillips Novo-Keynesiana Híbrida (CPNKH). Para tal, faz-se uso de informações mensais entre janeiro de 2002 e agosto de 2015 e estimações de GMM-HAC da CPNKH. Os resultados sugerem que a inflação brasileira ainda possui um forte componente inercial e que, em um ambiente de menor previsibilidade dos agentes, a inflação se mostra mais sensível às oscilações cíclicas da atividade econômica. Por fim, observou-se um repasse cambial positivo e significante para a inflação brasileira. PALAVRAS-CHAVE: Ciclos econômicos; expectativas; inflação.
\end{abstract}

ABSTRACT: This work analyzes how the recent Brazilian inflation responds to economic cycles and its inertial component considering different environments of forward-looking expectations in the framework of the Hybrid New-Keynesian Phillips Curve (HNKPC). To do this, use is made of monthly data from January 2002 to August 2015 and GMM-HAC estimates of the HNKPC. The results suggest that Brazilian inflation still has a strong inertial component and that in an environment of lower predictability of economic agents, inflation seems to be more sensitive to cyclical fluctuations in economic activity. Finally, it was observed a positive and significant pass-through exchange rate to inflation in Brazil. KEYWORDS: Economic cycles; expectations; inflation.

JEL Classification: E30; E31; E32.

\footnotetext{
* Respectivamente Professor do Departamento de Economia Aplicada da Universidade Federal do Ceará. E-mail: elano@ufc.br; Doutoranda em Economia no Programa de Pós-Graduação em Economia da Universidade Federal do Ceará. E-mail: thalitaoliveira.sobral@gmail.com; Professor Titular da Universidade Federal do Ceará. E-mail: lume1250@yahoo.com.br. Submetido: 16/Dezembro/2015; aprovado: 5/10/2016.
} 


\section{INTRODUÇÃO}

A curva de Phillips, inicialmente representada pelo trade-off entre inflação de salários e desemprego, passou por importantes transformações ao longo das últimas décadas. Tais modificações foram motivadas tanto pela evolução da teoria macroeconômica quanto pelo surgimento de novos fatos estilizados sobre a relação entre ciclos econômicos, expectativas e inflação.

A mais recente delas, baseada nas formulações de Taylor (1980) e Calvo (1983), ficou conhecida como a Curva de Phillips Novo-Keynesiana (CPNK); tal curva é derivada a partir de um modelo microfundamentado de expectativas racionais, o qual prevê uma relação entre inflação no curto prazo e uma medida de custo marginal das empresas, além de destacar a importância das expectativas na forma forward-looking. Adicionalmente, Galí e Gertler (1999) propuseram a chamada Curva de Phillips Novo-Keynesiana Híbrida (CPNKH), na qual se avalia também a participação do componente inercial, ou backward-looking, da inflação.

Atualmente, a CPNKH encontra-se no centro do debate em torno da condução da política monetária e da relação entre ciclos econômicos ${ }^{1}$, expectativas e inflação. De fato, essas evidências mostram-se relevantes, uma vez que uma autoridade monetária crível pode projetar uma política de desinflação sem custos se a inflação é um processo puramente forward-looking, enquanto, na presença de um componente backward-looking, a referida política poderia ter um maior custo em termos de atividade econômica.

$\mathrm{Na}$ literatura internacional, percebe-se certa polarização entre os estudos; ou seja, existem aqueles que mostram que a CPNKH é um mecanismo robusto para explicar a dinâmica inflacionária (Galí e Gertler, 1999; Galí, Gertler e Lopez-Salido, 2001) e os que questionam a sua relevância empírica (Rudd e Whelan, 2005). Para o Brasil, diversos estudos corroboraram a ideia de que a curva de Philips é importante para analisar o comportamento da inflação, apesar dos resultados serem bastante sensíveis aos métodos de estimação e às proxies adotadas para as variáveis do modelo (Mendonça, Sachsida e Medrano, 2012; Sachsida, 2013).

As principais evidências ${ }^{2}$ para a economia brasileira mostram a relevância estatística dos componentes de expectativas backward-looking e forward-looking no comportamento da inflação e a dificuldade da variável de ciclo econômico, medida pelo hiato do produto, em captar o efeito das mudanças na atividade econômica sobre a dinâmica inflacionária (Areosa e Medeiros, 2007; Sachsida, Ribeiro e Dos Santos, 2009; Arruda, Ferreira e Castelar, 2011).

Apesar do amplo debate em torno da adequação da CPNKH, pouco se tem discutido sobre como a dinâmica recente da inflação brasileira responde ao seu componente inercial, às oscilações cambiais (ou pass-through do câmbio) e aos

\footnotetext{
${ }^{1}$ Ou custo marginal das empresas.

${ }^{2}$ Uma boa revisão das principais evidências pode ser encontrada em Mendonça, Sachsida e Medrano (2012) e Sachsida (2013).
} 
ciclos da atividade econômica considerando diferentes níveis de previsibilidade dos agentes, ou expectativas forward-looking, na CPNKH. Autores como Mendonça (2002, 2004), Sicsú (2002) e Mendonça e Santos (2006) mostram que a credibilidade da autoridade monetária afeta o poder preditivo dos agentes econômicos e que boa parte da inércia da inflação é resultado da perda de reputação do governo em virtude do não cumprimento das regras previamente firmadas com os agentes.

Portanto, o presente estudo propõe-se a examinar o comportamento recente da inflação brasileira considerando ambientes distintos de expectativas forward-looking na CPNKH. Em outras palavras, deseja-se responder às seguintes questões: Como se comportam os coeficientes estimados da CPNKH em ambientes de expectativas forward-looking diferenciados? Caso os agentes econômicos possuam previsão perfeita, a inflação seria menos sensível às oscilações cíclicas do produto e ao seu componente inercial? Os custos de uma política de desinflação, em termos de redução na atividade econômica, aumentam num ambiente de menor previsibilidade dos agentes? Há significância estatística no repasse cambial para a inflação brasileira? Uma vez que autores como Simonsen (1970, 1985), Cabello (2014) e Carvalho (2014) alertam que a permanência ou o aumento da indexação tem reflexos importantes sobre a realimentação inflacionária, o possível aumento recente do grau de indexação da economia brasileira influenciou o impacto da inflação inercial?

Para tal, far-se-á uso de estimações da CPNKH para a economia brasileira com o método dos momentos generalizados consistente na presença de heterocedasticidade e autocorrelação (GMM-HAC) e informações mensais entre janeiro de 2002 a agosto de $2015^{3}$. Serão utilizados o hiato do produto, o hiato do desemprego e o custo marginal real das empresas ${ }^{4}$ como variáveis de ciclos econômicos; o repasse cambial, medido pela taxa de variação do câmbio nominal adicionada a um componente de inflação internacional, $\left(\Delta e_{t}+\pi_{t}^{*}\right)$, onde $e_{t}$ é o logaritmo da taxa de câmbio nominal, $\Delta$ é o operador de diferença e $\pi_{t}^{*}$ é uma medida da inflação internacional, índice de preços ao produtor americano (Correa e Minella, 2010; Arruda, Ferreira e Castelar, 2011); a inflação medida pelo Índice de Preços ao Consumidor Amplo (IPCA) defasada como medida de inflação inercial; o próprio IPCA adiantado como medida de expectativas forward-looking sob previsão perfeita (expectativas racionais) e, para um ambiente de incerteza, utilizar-se-ão três variáveis forward-looking, quais sejam, i) a mediana das expectativas de inflação em todos os dias do mês para o mês seguinte do relatório Focus do Banco Central do Brasil (Bacen), ii) as expectativas de inflação do primeiro dia do mês para o mês seguinte do relatório Focus do Bacen, e iii) a média das expectativas de inflação em todos os dias do mês para o mês seguinte do relatório Focus do Bacen.

Assim, a principal contribuição deste estudo reside na avaliação do comporta-

\footnotetext{
${ }^{3}$ Este período foi escolhido devido à disponibilidade de dados para as variáveis de desemprego e de custo marginal das empresas utilizadas.

${ }^{4}$ Medido em termos da razão Massa salarial/PIB.
} 
mento das respostas da inflação brasileira recente às oscilações nos ciclos econômicos, repasse cambial e ao seu componente inercial em ambientes distintos de expectativas forward-looking, além de testar o hiato do desemprego como medida de ciclo econômico ${ }^{5}$ e utilizar uma medida de custo marginal das empresas nos moldes de Galí e Gertler (1999). Vale destacar que a medida de custo marginal empregada neste estudo ainda não foi utilizada em aplicações para o Brasil ${ }^{6}$.

Além desta introdução, o presente estudo possui mais cinco seções. A seção seguinte apresenta aspectos teóricos sobre a curva de Phillips e sobre as relações entre ciclos econômicos, expectativas e inflação em ambientes distintos de expectativas. A terceira seção se reserva à descrição e análise dos dados. Na quarta seção apresenta-se a estratégia econométrica. Na quinta seção procede-se à análise e discussão dos resultados. E, por fim, são tecidas as considerações finais do estudo.

\section{REVISÃO DE LITERATURA}

\section{Curva de Phillips Tradicional}

A versão original da curva de Phillips mostra uma relação inversa entre inflação de salários e desemprego. Desse modo, em sua versão tradicional, a curva tem a seguinte especificação:

$$
\pi_{t}=\alpha+\gamma u_{t}+\varepsilon_{t}
$$

onde $\pi_{t}$ é a inflação de salários em $t, u_{t}$, é a taxa de desemprego corrente e $\alpha$, $\gamma$ são os parâmetros, onde $\gamma<0$.

Segundo Phillips (1958), uma taxa de desemprego elevada apontaria para um excesso de oferta de mão de obra e, consequentemente, haveria pressão para que os salários diminuíssem. Surgia, assim, o trade-off entre inflação e desemprego que as economias enfrentam na elaboração e execução de políticas econômicas. Estas dispunham do instrumental IS-LM para analisar o lado da demanda, junto com a curva de Phillips, que representava o lado da oferta.

No entanto, a crença de que uma variável nominal (inflação) afetava variáveis reais (taxa de desemprego) foi bastante criticada na segunda metade da década de 1960. Autores como Phelps $(1967,1969)$ e Friedman $(1968,1977)$ argumentaram que a formulação original da curva procura analisar o crescimento dos salários nominais ante as taxas de desemprego, o que contraria a hipótese de racionalidade dos agentes econômicos, uma vez que estes estão preocupados com a evolução de variáveis reais e não simplesmente de variáveis nominais. Dessa forma, esses auto-

\footnotetext{
${ }^{5}$ Variável extraída da relação de Okun, que prevê uma relação inversa entre os ciclos do produto e do desemprego.

${ }^{6}$ Normalmente se utiliza hiato do produto, hiato do desemprego, utilização da capacidade instalada da indústria, entre outros. Todavia, nenhum desses indicadores se refere efetivamente a uma medida de custo marginal das empresas.
} 
res defenderam a ideia de que a curva de Phillips precisava de um componente para captar as expectativas de inflação.

Com a taxa de desemprego reduzida e, com isso, elevada a taxa de inflação, os trabalhadores perceberiam que a inflação era maior do que a esperada e passariam a negociar os salários com base nessa nova expectativa; consequentemente, a taxa de desemprego voltaria ao seu estado original, pois os salários reais, que haviam diminuído, voltariam ao seu nível anterior. Essa ideia inicial de Muth (1961) seria chamada de expectativas adaptativas, ou backward-looking, pois os agentes corrigem suas expectativas com base nos erros de previsão passados; ou seja, a expectativa de inflação, $\pi_{t}^{e}$, seria modelada como uma média ponderada das inflações passadas atribuindo-se maiores pesos para as informações mais recentes. Ou seja, a curva de Phillips assumiria a forma:

$$
\pi_{t}=\vartheta \pi_{t}^{e}+\gamma\left(u_{t}-u_{n}\right)+\varepsilon_{t}
$$

sendo $\pi_{t}$ a inflação corrente, $\pi_{t}^{e}$ a expectativa de inflação para $t$, dada por uma média ponderada das inflações passadas, $u_{t}$, a taxa de desemprego corrente e $u_{n}$, a taxa de desemprego natural.

Desse modo, as expectativas dos agentes passaram a ser fundamentais na construção e execução de políticas econômicas. Entretanto, constatou-se posteriormente que, com base nas expectativas adaptativas, os agentes econômicos cometeriam erros sistemáticos de previsão, fato que não se mostra razoável na realidade.

Esta constatação gerou uma profunda reformulação na teoria macroeconômica entre as décadas de 1970 e 1980, impulsionada pela hipótese de expectativas racionais, ou forward-looking, atribuídas a Lucas (1972) e Sargent (1971). Segundo esses autores, os agentes econômicos levam em consideração, ao definir a inflação esperada, todo o conjunto informacional ao seu alcance até o período corrente, e não apenas uma combinação das informações passadas. Assim, $\pi_{t}^{e}$ passa a ser função do conjunto de informações disponíveis até $t$, surgindo a necessidade de um componente forward-looking para a curva de Phillips.

\section{Curva de Phillips Novo-Keynesiana (CPNK)}

Nas últimas décadas, uma nova abordagem da curva de Phillips tem sido amplamente discutida. Taylor (1980) e Calvo (1983) lançaram as bases para a moderna análise da inflação examinando a escolha dos preços e salários numa perspectiva forward-looking por parte das famílias e firmas. Nessa versão, a curva é deduzida como uma relação entre a inflação e o custo marginal das empresas. Essa formulação, denominada de Curva de Phillips Novo-Keynesiana (CPNK), parte de duas equações estruturais; ou seja,

$$
\begin{aligned}
& p_{t}=\theta p_{t-1}+(1-\theta) p_{t}^{*} \\
& p_{t}^{*}=(1-\beta \theta) \sum_{k=0}^{\infty}(\beta \theta)^{k} E_{t}\left\{c m_{t+k}^{n}\right\}
\end{aligned}
$$


Na equação (3), $p_{t}$ é nível de preços agregado e $p_{t}^{*}$ é o nível de preços derivado da maximização do lucro das firmas, ambos em logaritmo, e $\theta(0<\theta<1)$ define a fração de firmas que não ajustam os seus preços via otimização de lucros em $t$. Ou seja, a equação (3) introduz certa rigidez de preços, uma vez que apenas uma fração $(1-\theta)$ das firmas pode ajustar otimamente os seus preços em $t$ e as demais mantêm o nível de preços do período anterior.

A equação (4) pode ser derivada formalmente a partir da maximização do valor presente do lucro esperado por parte das firmas e especifica o preço ótimo escolhido pelas firmas como função de $\theta$, do custo marginal real, $\mathrm{cm}_{t+k}^{n}$, e de um fator de desconto $\beta$ (Calvo, 1983). Ou seja, na ausência de friç̧ões ou custos de ajustamento, as empresas definiriam seus preços iguais ao custo marginal em cada período. Entretanto, as firmas não mudam seus preços em todos os períodos, por isso a definição de $p_{t}^{*}=c m_{t+k}^{n}$ não é adequada nesse contexto; logo, os preços devem ser formados a partir da expectativa do comportamento do custo marginal esperado de modo a maximizar o valor presente do lucro esperado. Assim, definindo a inflação em $t$ como $\pi_{t}=p_{t}-p_{t-1}$ e combinando as equações (3) e (4) encontra-se a CPNK expressa como,

$$
\pi_{t}=\lambda c m_{t}+\gamma_{f} E_{t}\left\{\pi_{t+1}\right\}
$$

Ou seja, a inflação corrente será função do custo marginal real das empresas em $t$ e da expectativa de inflação, sendo esta construída de forma forward-looking. Galí e Gertler (1999) mostram que existe uma relação entre o custo marginal e hiato do produto ${ }^{7}$ expressa como,

$$
c m_{t}=k x_{t}
$$

onde $k$ é a elasticidade do custo marginal real em relação ao hiato do produto. Desse modo, substituindo-o na equação (5), tem-se que,

$$
\pi_{t}=\lambda k x_{t}+\gamma_{f} E_{t}\left\{\pi_{t+1}\right\}
$$

Portanto, a inflação em $t, \pi_{t}$, será expressa como função da taxa de inflação esperada para o próximo período, $E_{t}\left\{\pi_{t+1}\right\}$; isto é, um termo forward-looking, e por uma medida do ciclo econômico, $x_{t}$. Assim, a CPNK pode ser estimada utilizando variáveis de custo marginal das empresas e de ciclos econômicos ${ }^{8}$.

\section{A Curva de Phillips Novo-Keynesiana Híbrida}

Apesar disso, a CPNK ainda apresenta uma importante lacuna, visto que não

\footnotetext{
${ }^{7} \mathrm{O}$ desvio (em log) do produto de seu nível produto potencial. Ou seja, $x_{t} \equiv \hat{Y}_{t}-\hat{Y}_{t}^{n}$.

${ }^{8} \mathrm{O}$ presente estudo fará uso do hiato do produto e do hiato do desemprego como medidas de ciclos econômicos.
} 
inclui um componente inercial ou backward-looking na inflação, o que motivou o surgimento da versão que ficou conhecida como forma híbrida da CPNK (Gali e Gertler, 1999). Neste contexto, $p_{t}^{*}$ assume a forma:

$$
p_{t}^{*}=(1-\omega) p_{t}^{f}+\omega p_{t}^{b}
$$

em que $p_{t}^{f}$ é o preço fixado pelas empresas que usam expectativas forward-looking e $p_{t}^{b}$ é o preço do conjunto de firmas que usam expectativas na forma backward-looking. . O primeiro grupo de empresas comporta-se exatamente como no modelo descrito por Calvo (1983). Logo, $p_{t}^{f}$ será:

$$
p_{t}^{f}=(1-\beta \theta) \sum_{k=0}^{\infty}(\beta \theta)^{k} E_{t}\left\{c m_{t+k}^{n}\right\}
$$

Em relação ao preço das empresas que formam suas expectativas de forma backward-looking, ele será expresso como o nível de preços no último período corrigido pela inflação. Formalmente,

$$
p_{t}^{b}=p_{t-1}^{*}+\pi_{t-1}
$$

Portanto, combinando as equações (3), (8), (9) e (10) pode-se derivar a versão híbrida da CPNK; ou seja,

$$
\pi_{t}=\lambda c m_{t}+\gamma_{f} E_{t}\left\{\pi_{t+1}\right\}+\gamma_{b} \pi_{t-1}
$$

onde, $\gamma_{f}$ é o parâmetro do termo forward-looking, $\gamma_{b}$ incorpora o componente backward-looking da inflação e $\lambda$ incorpora a contribuição do custo marginal das empresas/ciclos econômicos. Agora, $\gamma_{b}$ passa a indicar o grau de persistência inflacionária. Vale destacar que, caso $\gamma_{f}$ seja estatisticamente igual à zero, tem-se a formulação tradicional da curva de Phillips.

Mais recentemente, a discussão em torno dos impactos de choques de oferta, como as oscilações cambiais, sobre a dinâmica inflacionária propiciou a formulação de Blanchard e Galí (2007) da Curva de Phillips Novo-Keynesiana Híbrida, que pode ser representada como:

$$
\pi_{t}=\lambda c m_{t}+\gamma_{f} E_{t}\left\{\pi_{t+1}\right\}+\gamma_{b} \pi_{t-1}+\theta v_{t}
$$

onde $\theta$ mede o impacto dos choques de oferta na inflação. Tradicionalmente, o indicador $v_{t}$ tem sido utilizado como uma medida de repasse cambial para a inflação; ou seja, uma desvalorização cambial implica um aumento dos custos das empresas que utilizam insumos importados em seu processo produtivo, o que pode significar uma situação de prejuízo ou redução de seu markup. Para evitar essas perdas, as

\footnotetext{
${ }^{9}$ Uma fração $\omega$ das empresas formam expectativas nos moldes backward-looking enquanto (1- $\omega$ ) fazem suas projeções na forma forward-looking.
} 
empresas tenderiam a repassar mais rapidamente as variações cambiais. No caso de valorização cambial, esse processo repercute positivamente no lucro dessas empresas, o que poderia levar a um maior tempo para reajustar os preços para baixo.

Adicionalmente, autores como Blonigen e Hayes (1999), Gil-Pareja (2003) e a literatura de princing-to-market concluem que uma desvalorização cambial deixa as empresas multinacionais com as seguintes escolhas: i) reduzir seu markup para manter o preço do produto na moeda do país "doméstico" (nesse caso, não ocorre o pass-through); ii) manter seu markup, aumentando o preço cobrado no país "doméstico" para refletir completamente a variação do câmbio (pass-through integral), o que pode implicar uma redução de sua parcela de mercado; ou, ainda, iii) uma combinação das possibilidades anteriores (pass-through parcial).

Nesse sentido, estudos recentes realizados para o Brasil que incorporam essa análise utilizam como indicador de repasse do câmbio para a inflação doméstica a taxa de variação do câmbio nominal adicionada de uma medida de inflação externa (PPI americano) (Correa e Minella, 2010; Arruda, Ferreira e Castelar, 2011).

\section{Evidências empíricas para o Brasil}

Essa subseção é reservada à apresentação das evidências empíricas na literatura brasileira sobre a adequação da curva de Phillips à dinâmica inflacionária do Brasil e em que magnitude os ciclos econômicos, as expectativas backward-looking (inflação inercial) e forward-looking, e o repasse cambial influenciam a inflação brasileira.

Portugal, Madalozzo e Hillbrecht (1999) fazem uso de informações trimestrais entre 1982 a 1998 e encontram uma relação estatisticamente significante entre inflação e desemprego, com coeficiente estatisticamente robusto da ordem de $-1,745$. As variáveis de expectativas backward-looking e forward-looking não se mostram significantes. Como proxy para a inflação, os autores adotam o Índice Nacional de Preços ao Consumidor (INPC), elaborado pelo Instituto Brasileiro de Geografia e Estatística (IBGE). Os autores utilizam a Pesquisa Mensal de Emprego (PME) do IBGE como a Pesquisa de Emprego e Desemprego (PED) do Departamento Intersindical de Estatística e Estudos Socioeconômicos (Dieese)/Fundação Sistema Estadual de Análise de Dados (Seade) para extraírem a taxa de desemprego. As variáveis de expectativas forward-looking são construídas a partir da aplicação de técnicas autorregressivas de séries temporais.

Posteriormente, Portugal e Madalozzo (2000) confirmam a significância estatística do trade off entre inflação e desemprego para o Brasil com uso de dados trimestrais para o período de 1982:3 a 1997:3. As variáveis empregadas foram: a inflação (INPC do IBGE); o desemprego (desemprego aberto, 30 dias - tanto da PME, do IBGE, quanto da PED, do Dieese); e a expectativa de inflação forward-looking (extraída a partir de um processo autorregressivo AR(1)). Os autores encontram um coeficiente significante da ordem de $-3,37$ para o impacto da taxa de desemprego.

Como os estudos anteriores que buscavam estimar a NAIRU (a taxa de desemprego que não acelera a inflação), Lima (2003) amplia o debate e discute também a estabilidade da curva de Phillips com dados trimestrais de 1982:1 a 2001:4 para a economia brasileira. Para lidar com possíveis quebras estruturais, o autor estima 
um modelo com coeficientes variando no tempo (TVP) e resíduos controlados por heterocedasticidade condicional (ARCH) e outro modelo com mudanças de regime de Markov (MSR). Os resultados apontam para adequação e estabilidade da curva de Phillips para os dados brasileiros. A NAIRU estimada pelo TVP indica que um aumento permanente de $0,5 \%$ do desemprego cíclico, depois de 3 trimestres, reduz em $7,5 \%$ a inflação mensal anualizada. Ao analisar os resultados da estimação por MSR, após 1 trimestre, a inflação se reduz em 5\%.

Minella et al. (2003) fazem uso de dados mensais entre 1995:07 e 2002:12 para estimar a curva de Phillips e avaliar como a meta de inflação influencia a formação das expectativas. Os autores atestam que a inflação esperada reage positiva e significativamente à meta de inflação. As variáveis empregadas foram a inflação, o Índice de Preços ao Consumidor Amplo (IPCA); o desemprego, a taxa de desemprego sazonalmente ajustada de 30 dias (IBGE). Na modelagem da curva de Phillips, encontram coeficientes que variam entre 0,56 e 0,62 para a inflação inercial e -0,09 para o desemprego.

Utilizando dados mensais entre 1990:1 e 2002:8, Fasolo e Portugal (2004) examinam a relação entre inflação e emprego no Brasil a partir de quatro hipóteses novo-keynesianas, quais sejam, os agentes não possuem racionalidade perfeita; a imperfeição na formação de expectativas pode ser determinante no componente inercial da inflação brasileira; a inflação possui componente inercial autônomo; e, por fim, as relações não lineares entre inflação e desemprego fornecem melhores resultados para o período em questão. Os testes econométricos confirmam as quatro hipóteses. Analisando a curva de Phillips, os coeficientes da inflação inercial se mostraram estatisticamente significantes e da ordem 0,13 (amostra inteira), 0,30 (de 1990:1 a 1994:6) e 0,10 (de 1995:1 a 2002:8); o impacto das expectativas forward-looking foi de 0,82 (amostra inteira), 0,44 (de 1990:1 a 1994:6), ambos estatisticamente robustos, e não se mostrou significante para 1995:1 a 2002:8.

Muinhos (2004) estima modelos da curva de Phillips para o Brasil com dados trimestrais de 1994:4 a 2002:2, utilizando como medida de ciclo econômico o hiato do produto, estimado como a diferença entre o PIB e sua tendência linear. A variável de inflação empregada é o IPCA e o indicador de expectativas forward-looking foi extraído a partir de previsões geradas por modelos ARMA. Curiosamente, o autor não inclui o componente inercial e o forward-looking juntos no mesmo modelo. Os coeficientes estimados foram: ciclos econômicos 0,28 (no modelo linear) e 0,41 (no modelo não linear); expectativas backward-looking 0,51 (no modelo linear) e 0,45 (no modelo não linear); e, por fim, expectativas forward-looking 1,18 (no modelo linear) e 1,29 (no modelo não linear).

Para analisar o comportamento da curva de Phillips com preços desagregados (comercializáveis e não comercializáveis), Schwartzman (2006) faz uso de dados trimestrais entre 1997 e 2003 e do método de mínimos quadrados em três estágios. $\mathrm{O}$ autor considera a utilização da capacidade da indústria (Fundação Getulio Vargas - FGV) como variável de ciclos econômicos, a inflação medida pelo IPCA cheio e o repasse cambial, calculado a partir da inflação medida pelo PPI americano. Os coeficientes estimados para os não comercializáveis foram os seguintes: ciclos eco- 
nômicos, entre 0,71 e 1,27 e inflação inercial, entre 0,39 e 0,50. Para o modelo que considera os comercializáveis, a inércia inflacionária foi da ordem de 0,37 a 0,56 , o repasse cambial apresentou coeficiente de 0,14 e o indicador de ciclos não se mostrou significante nesse modelo.

Tombini e Alves (2006) utilizam dados mensais entre janeiro de 1996 e janeiro de 2006 e estimam uma curva de Phillips híbrida com parâmetros variáveis. Os autores observam que vários coeficientes se movem para patamares distintos na mudança para o câmbio flexível, em 1999. Seus resultados não apontam para a significância estatística do hiato do produto como indicador de ciclos econômicos. $\mathrm{O}$ impacto das expectativas backward-looking e forward-looking se mostraram semelhantes e entre 0,1 e 0,3 .

Avaliando se a inclusão de um indicador de credibilidade da política monetária melhora o poder preditivo da curva de Phillips no período pós-metas de inflação, Mendonça e Santos (2006) utilizam dados mensais, entre abril de 2000 e abril de 2005, do desemprego medido pela taxa de desemprego aberto da PED (Dieese/ Seade) da Região Metropolitana de São Paulo, da inflação IPCA e das expectativas de inflação disponibilizadas pelo Banco Central do Brasil. Os resultados confirmam que a utilização de uma medida de credibilidade na curva de Phillips melhora o seu poder preditivo. Os coeficientes estimados para as expectativas forward-looking apresentam valores entre 0,43 e 0,96 , e o hiato do desemprego apresenta impacto entre $-0,01$ e $-0,08$ sobre a inflação.

Areosa e Medeiros (2007) estimam uma curva de Phillips Novo-Keynesiana Híbrida pelo Método dos Momentos Generalizados (GMM) utilizando dados mensais para o período de 1995:1 a 2003:9. Os resultados apontam que i) a inflação inercial é um componente não desprezível, com estimativas significantes ao redor de 0,45 ; ii) as expectativas forward-looking apresenta impacto superior, com valores ao redor de 0,53 ; e iii) o impacto dos ciclos econômicos, medido pelo hiato do produto, não se mostra estatisticamente significante.

Utilizando dados trimestrais de 1995:1 a 2008:4 e técnicas de variáveis instrumentais (IV) e GMM, Mazali e Divino (2010) estimam a curva de Phillips tendo como indicadores: o IPCA para a inflação, e a taxa de desemprego aberta, sazonalmente ajustada, para a Região Metropolitana de São Paulo (Dieese), para o desemprego. Os resultados econométricos atestam o bom grau de ajustamento da curva de Phillips aos dados brasileiros e os coeficientes estimados foram da ordem de 0,59 para a inércia inflacionária, 0,44 para as expectativas futuras de inflação e -0,13 para o desemprego.

Investigando a presença de mecanismos não lineares no repasse cambial para a inflação, Correa e Minella (2010) estimam uma curva de Phillips não linear com dados trimestrais entre 1995:1 e 2004:4 considerando três variáveis threshold para captar a mudança de regime; quais sejam, hiato do produto, a oscilação do câmbio nominal e a volatilidade do câmbio (medida pelo desvio-padrão das variações diárias da taxa de câmbio dentro de cada trimestre). No primeiro caso, os coeficientes estimados das expectativas forward-looking e backward-looking são 0,62 e 0,29, respectivamente, o impacto dos ciclos é de 0,15 e o repasse cambial foi da ordem de 0,09 . No segundo modelo, o coeficiente da inércia inflacionária foi de 0,34 , o das 
expectativas forward-looking foi 0,63 , e os impactos do repasse cambial e ciclos econômicos foram 0,10 e 0,22 , respectivamente. Por fim, a influência das expectativas forward-looking e backward-looking foi de 0,66 e 0,30, respectivamente, os ciclos passaram a impactar na ordem de 0,20 e o coeficiente do repasse cambial foi de 0,04.

Quadro 1: Quadro resumo das evidências para o Brasil

\begin{tabular}{|c|c|c|c|c|c|}
\hline Autores & $\begin{array}{c}\text { Inércia } \\
\text { Inflacionária }\end{array}$ & $\begin{array}{l}\text { Expectativas } \\
\text { forward- } \\
\text {-looking }\end{array}$ & $\begin{array}{c}\text { Ciclos } \\
\text { Econômicos }\end{array}$ & $\begin{array}{l}\text { Repasse } \\
\text { cambial }\end{array}$ & Amostra \\
\hline $\begin{array}{l}\text { Portugal, Madalozzo } \\
\text { e Hillbrecht (1999) }\end{array}$ & NS & NS & $-1,74$ & - & 1982T1 a 1998T4 \\
\hline Portugal e Madalozzo (2000) & NS & NS & $-3,37$ & - & 1982:Т3 а 1997Т3 \\
\hline Minella et al. (2003) & $\begin{array}{c}\text { entre } \\
0,56 \text { e } 0,62\end{array}$ & - & $-0,09$ & - & 1995:M7 a 2002:M12 \\
\hline Fasolo e Portugal (2004) & 0,13 & 0,82 & - & - & 1990:M1 a 2002:M8 \\
\hline Fasolo e Portugal (2004) & 0,30 & 0,44 & - & - & 1990:M1 a 1994:M6 \\
\hline Fasolo e Portugal (2004) & 0,10 & NS & - & - & 1995:M1 a 2002:M7 \\
\hline Muinhos (2004) - Linear & 0,51 & - & 0,28 & - & 1994:M4 a 2002:M2 \\
\hline Muinhos (2004) - Linear & - & 1,18 & 0,35 & - & 1994:M4 a 2002:M2 \\
\hline Muinhos (2004) - Não Linear & 0,45 & - & 0,41 & - & 1994:M4 a 2002:M2 \\
\hline Muinhos (2004) - Não Linear & - & 1,29 & 0,42 & - & 1994:M4 a 2002:M2 \\
\hline Schwartzman (2006) & $\begin{array}{c}\text { entre } \\
0,37 \text { a } 0,56\end{array}$ & - & $\begin{array}{c}\text { entre } \\
0,71 \text { e } 1,27\end{array}$ & 0,14 & 1997:T1 a 2003:T3 \\
\hline Tombini e Alves (2006) & $\begin{array}{c}\text { entre } \\
0,1 \text { e } 0,3\end{array}$ & $\begin{array}{c}\text { entre } \\
0,1 \text { e } 0,3\end{array}$ & NS & - & 1996:M1 a 2006:M1 \\
\hline $\begin{array}{c}\text { Mendonça } \\
\text { e Santos (2006) }\end{array}$ & - & $\begin{array}{c}\text { entre } \\
0,43 \text { e } 0,96\end{array}$ & $\begin{array}{c}\text { entre } \\
-0,01 \text { e }-0,08\end{array}$ & - & 2000:M4 a 2005:M4 \\
\hline $\begin{array}{c}\text { Areosa } \\
\text { e Medeiros (2007) }\end{array}$ & 0,45 & 0,53 & NS & - & 1995:M1 a 2003:M9 \\
\hline Mazali e Divino (2010) & 0,59 & 0,44 & $-0,13$ & - & 1995:M1 a 2008:M4 \\
\hline $\begin{array}{l}\text { Correa e Minella } \\
\text { (2010) - modelo1 }\end{array}$ & 0,29 & 0,62 & 0,15 & 0,09 & 1995:T1 e 2004:T4 \\
\hline $\begin{array}{l}\text { Correa e Minella } \\
\text { (2010) - modelo } 2\end{array}$ & 0,34 & 0,63 & 0,22 & 0,10 & 1995:T1 e 2004:T4 \\
\hline $\begin{array}{l}\text { Correa e Minella } \\
\text { (2010) - modelo } 3\end{array}$ & 0,30 & 0,66 & 0,20 & 0,04 & 1995:T1 e 2004:T4 \\
\hline $\begin{array}{c}\text { Arruda, Ferreira e Castelar } \\
\qquad \text { (2011) - Linear }\end{array}$ & 0,71 & - & NS & 1,58 & 1995:M1 a 2005:M12 \\
\hline $\begin{array}{c}\text { Arruda, Ferreira e } \\
\text { Castelar (2011) - Não Linear }\end{array}$ & 0,69 & - & NS & 2,62 & 1995:M1 a 2005:M12 \\
\hline $\begin{array}{l}\text { Mendonça, Sachida } \\
\text { e Medrano (2012) }\end{array}$ & $\begin{array}{c}\text { entre } \\
0,41 \text { e } 0,52\end{array}$ & $\begin{array}{c}\text { entre } \\
0,25 \text { e } 0,53\end{array}$ & NS & $\begin{array}{c}\text { entre } \\
0,26 \text { e } 0,55\end{array}$ & 1995:M1 a 2012:M3 \\
\hline $\begin{array}{l}\text { Mendonça, Sachida } \\
\text { e Medrano (2012) }\end{array}$ & 0,39 & $\begin{array}{c}\text { entre } 0,63 \text { e } \\
0,67\end{array}$ & NS & NS & 2002:M1 a 2012:M3 \\
\hline
\end{tabular}

Notas: (NS) Não Significante; (-) Não utilizou a variável; (T) - Dados trimestrais; (M) - Dados mensais. 
Arruda, Ferreira e Castelar (2011) estimam modelos lineares e não lineares da curva de Phillips e de séries temporais com o propósito de prever a inflação do Brasil. Os autores observam que a curva de Phillips não linear, ampliada pelo repasse cambial, apresentou o melhor desempenho de previsão entre todos os modelos considerados, atestando a robustez dessa relação para realização de projeções para a economia brasileira. Os coeficientes estimados da curva de Phillips linear foram: 0,71 para a inércia inflacionária e 1,58 para o repasse cambial, ambos significantes; já no modelo não linear (em um regime de inflação elevada), a inflação passada apresentou impacto de 0,69 e o repasse da taxa de câmbio para a inflação é de 2,62. Em todos os modelos empregados, o hiato do produto não se mostrou estatisticamente significante.

Utilizando informações mensais entre janeiro de 1995 e março de 2012 e os métodos de variáveis instrumentais (IV) e de GMM, Mendonça, Sachida e Medrano (2012) estimam modelos para a Curva de Phillips Novo-Keynesiana Híbrida para o Brasil. Os autores observam coeficientes estimados entre 0,25 e 0,53, para o componente forward-looking das expectativas; entre 0,41 e 0,52, para a inércia inflacionária; e entre 0,26 e 0,55 para o repasse cambial, considerando a amostra completa. Considerando o modelo entre janeiro de 2002 e março de 2012, os coeficientes estimados variam entre 0,63 e 0,67, para as expetativas forward-looking e 0,39 para a inflação defasada.

A exposição acima revela que não há um consenso sobre a adequação da curva de Phillips aos dados da economia brasileira, uma vez que os resultados se mostram bastante sensíveis às proxies empregadas, como argumenta Sachsida (2013). O Quadro 1, apresentado acima, apresenta uma síntese descritiva dos principais resultados da literatura brasileira. Diante do exposto, o presente trabalho traz como contribuição a essa literatura uma avaliação do comportamento da dinâmica inflacionária recente do Brasil diante de oscilações nos ciclos econômicos, no repasse cambial e em seu componente inercial em ambientes distintos de expectativas forward-looking (ou de previsibilidade dos agentes econômicos), além de testar o hiato do desemprego como medida de ciclo econômico e utilizar uma medida de custo marginal das empresas, nos moldes de Galí e Gertler (1999), que ainda não foi utilizada em aplicações para o Brasil.

\section{BANCO DE DADOS}

Para a estimação da CPNKH foram coletadas informações mensais entre janeiro de 2002 e agosto de 2015. O período amostral foi escolhido devido à disponibilidade de dados para as variáveis de custo marginal real das empresas e hiato do desemprego ${ }^{10}$. O Quadro 2 apresenta uma síntese das variáveis utilizadas.

\footnotetext{
${ }^{10}$ As informações necessárias para a construção dessas proxies para o Brasil apenas estão disponíveis
} 
O Índice Nacional de Preços ao Consumidor Amplo ${ }^{11}$ (IPCA) é a proxy para a inflação. As informações foram obtidas junto ao banco de dados do Instituto de Pesquisa Econômica Aplicada (IPEADATA), tendo como fonte o Sistema Nacional de Preços ao Consumidor (SNIPC) do Instituto Brasileiro de Geografia e Estatística (IBGE). Além deste indicador ser a inflação tratada como oficial pelo governo, é também o mais presente em estudos aplicados para o Brasil (Schwartzman, 2006; Areosa e Medeiros, 2007; Arruda, Ferreira e Castelar, 2011; Mendonça, Sachsida e Medrano, 2012; Sachsida, 2013).

Quadro 2: Descrição das Variáveis Utilizadas

\begin{tabular}{|c|c|c|c|}
\hline INDICADOR & VARIÁVEL & PROXY & FONTE \\
\hline Inflação & Inflação & Inflação IPCA & IBGE/SNIPC \\
\hline \multirow{5}{*}{ Expectativas } & \multirow{4}{*}{$\begin{array}{l}\text { Expectativa } \\
\text { Foward-Looking }\end{array}$} & $\begin{array}{l}\text { Inflação IPCA adiantado } \\
\text { (Previsão Perfeita/Expectativas } \\
\text { Racionais) }\end{array}$ & IBGE/SNIPC \\
\hline & & $\begin{array}{l}\text { Previsão FOCUS Mediana } \\
\text { (Expectativa declarada) }\end{array}$ & Relatório Focus Bacen \\
\hline & & $\begin{array}{l}\text { Previsão FOCUS } 1^{\circ} \text { dia } \\
\text { (Expectativa declarada) }\end{array}$ & Relatório Focus Bacen \\
\hline & & $\begin{array}{l}\text { Previsão FOCUS Média } \\
\text { (Expectativa declarada) }\end{array}$ & Relatório Focus Bacen \\
\hline & $\begin{array}{l}\text { Expectativa } \\
\text { Backward-Looking }\end{array}$ & Inflação IPCA defasado & IBGE/SNIPC \\
\hline \multirow{3}{*}{$\begin{array}{l}\text { Ciclos } \\
\text { Econômicos }\end{array}$} & $\begin{array}{l}\text { Custo Marginal } \\
\text { Real }\end{array}$ & Massa salarial/PIB & $\begin{array}{l}\text { Construída a partir } \\
\text { de dados do Bacen } \\
\text { e PME/IBGE }\end{array}$ \\
\hline & $\begin{array}{l}\text { Ciclo do } \\
\text { Produto }\end{array}$ & Hiato de Produto & $\begin{array}{l}\text { Construída a partir } \\
\text { de dados do Bacen } \\
\text { e Filtro HP }\end{array}$ \\
\hline & $\begin{array}{l}\text { Ciclo do } \\
\text { Desemprego }\end{array}$ & Hiato do Desemprego & $\begin{array}{l}\text { Construída a partir de } \\
\text { dados da Seade/PED } \\
\text { e Filtro HP }\end{array}$ \\
\hline Pass-through & Repasse Cambial & $\begin{array}{l}\text { Taxa de variação do câmbio } \\
\text { nominal acrescido de } \\
\text { uma medida de inflação } \\
\text { internacional (PPI Americano) }\end{array}$ & $\begin{array}{l}\text { Construída a partir dos } \\
\text { dados DEPEC/BACEN } \\
\text { e IFS/FMI }\end{array}$ \\
\hline
\end{tabular}

Fonte: Elaborado pelos autores.

a partir de outubro de 2001. No caso do desemprego, a metodologia foi modificada e a nova série também está disponível a partir de outubro de 2001.

${ }^{11}$ A população-alvo do IPCA abrange as famílias com rendimentos mensais compreendidos entre 1 e 40 salários mínimos para qualquer fonte de rendimentos, incluindo residentes nas áreas urbanas das regiões metropolitanas. 
Para considerar ambientes distintos de expectativas forward-looking, quatro variáveis foram utilizadas; quais sejam: uma de previsão perfeita sob expectativas racionais ${ }^{12}$, onde se utiliza o próprio IPCA adiantado, que é uma forma para a modelagem das expectativas forward-looking (Correa e Minella, 2010; Sachsida, Ribeiro e Dos Santos, 2009); e três indicares de previsão para um ambiente de menor previsibilidade dos agentes, quais sejam, a média, a mediana e a expectativa do primeiro dia do mês para o mês seguinte do relatório FOCUS do Bacen (Mendonça, Sachsida e Medrano, 2012; Sachsida, 2013).

A variável que incorpora o componente inercial, ou backward-looking, da inflação utilizada é o IPCA defasado. Essa medida é tradicionalmente empregada na maioria dos estudos para o Brasil (Schwartzman, 2006; Areosa e Medeiros, 2007; Arruda, Ferreira e Castelar, 2011; Mendonça, Sachsida e Medrano, 2012; Sachsida, 2013).

Três medidas do ciclo econômico foram utilizadas neste trabalho; a saber, custo marginal real das firmas, hiato do produto e o hiato do desemprego. As variáveis de hiato do produto e do desemprego foram construídas a partir da aplicação do filtro de Hodrick-Prescott ${ }^{13}(\mathrm{HP})$. O hiato do desemprego será incluído como alternativa em virtude da relação de Okun, que preconiza uma relação inversa entre os ciclos do produto e do desemprego.

O custo marginal real das empresas foi construído nos moldes de Galí e Gertler (1999) a partir do produto das séries de rendimento médio real efetivo das pessoas ocupadas e o total de empregados ${ }^{14}$, ambas oriundas da Pesquisa Mensal de Emprego (PME) do IBGE, dividindo-se o resultado pelo Produto Interno Bruto (PIB), fornecido pelo Banco Central do Brasil.

Por fim, nos moldes de Correa e Minella (2010) e Arruda, Ferreira e Castelar (2011), utilizou-se como indicador de repasse cambial para a inflação a variável $\left(\Delta e_{t}+\pi_{t}^{*}\right)$, em que $e_{t}$ é a taxa de câmbio nominal em logaritmo, $\Delta$ é o operador de diferença, e $\pi_{t}^{*}$ é a inflação ao produtor americana (PPI americano).

Vale ressaltar que, inicialmente, todas as variáveis foram submetidas aos testes

\footnotetext{
12 Vale destacar que, apesar de ser usualmente empregada na literatura, essa proxy para as expectativas forward-looking retrata um cenário hipotético em que os agentes econômicos conhecem o modelo macroeconômico que rege a economia e, com base nele, formam previsões perfeitas (expectativas racionais). Apesar disso, o método de estimação empregado neste estudo controla os possíveis problemas de endogeneidade oriundos da inclusão dessa variável nos modelos empregados.

${ }^{13}$ Vale destacar que o hiato do produto com o produto potencial extraído a partir da aplicação do filtro de Hodrick-Prescott é uma medida limitada, tanto pelo caráter ad hoc da modelagem como pelo fato de a tendência estimada representar um produto de steady-state que pode não representar fielmente o produto potencial. Por isso, normalmente esse indicador não apresenta impactos estatisticamente robustos sobre a inflação.

${ }^{14}$ Definido como aquelas pessoas que trabalham para um empregador ou mais, cumprindo uma jornada de trabalho, recebendo em contrapartida uma remuneração em dinheiro ou outra forma de pagamento (moradia, alimentação, vestuário etc.). Os empregados são classificados segundo a existência ou não de carteira de trabalho assinada.
} 
ADF, Phillips e Perron e KPSS de raiz unitária e se mostraram estacionárias aos níveis usuais de significância. Os resultados estão sintetizados na Tabela 1.

Tabela 1: Resultados dos Testes de Raiz Unitária

\begin{tabular}{cccc}
\hline VARIÁVEL & ADF & PP & KPSS \\
\hline Inflação & $-5,07$ & $-5,23$ & 0,24 \\
IPCA & {$[-2,87]$} & {$[-2,87]$} & {$[0,46]$} \\
\hline Previsão FOCUS & $-4,73$ & $-4,64$ & 0,35 \\
Mediana & {$[-2,87]$} & {$[-2,87]$} & {$[0,46]$} \\
\hline Previsão FOCUS & $-4,35$ & $-6,36$ & 0,22 \\
Média & {$[-2,87]$} & {$[-2,87]$} & {$[0,46]$} \\
\hline Previsão FOCUS & $-4,76$ & $-4,88$ & 0,30 \\
1 $^{\circ}$ dia & {$[-2,87]$} & {$[-2,87]$} & {$[0,46]$} \\
\hline Custo Marginal & $-5,95$ & $-8,45$ & 0,06 \\
Real & {$[-3,44]$} & {$[-3,43]$} & {$[0,14]$} \\
\hline Hiato & $-4,08$ & $-6,52$ & 0,03 \\
do Produto & {$[-2,87]$} & {$[-2,87]$} & {$[0,46]$} \\
\hline Hiato & $-6,02$ & $-4,67$ & 0,02 \\
do desemprego & {$[-2,87]$} & {$[-2,87]$} & {$[0,46]$} \\
\hline Repasse & $-15,33$ & $-15,08$ & 0,22 \\
Cambial & {$[-2,87]$} & {$[2,87]$} & {$[0,42]$} \\
\hline
\end{tabular}

Fonte: Elaboração própria a partir dos resultados obtidos. Valor crítico do teste no nível de significância $5 \%$ entre colchetes. Vale ressaltar que a hipótese nula dos testes ADF e PP é a de que as séries possuem raiz unitária, enquanto no KPSS é a de que as séries são estacionárias.

\section{ESTRATÉGIA ECONOMÉTRICA}

Um método amplamente utilizado para a estimação de modelos de expectativas racionais é o Método dos Momentos Generalizados (GMM), introduzido por Hansen (1982), uma vez que, nessas condições, o método de Mínimos Quadrados Ordinários (MQO) pode gerar estimativas inconsistentes devido ao fato do termo de erro estar correlacionado com alguns dos regressores endógenos. Outra alternativa à estimação desses modelos é utilizar o método de variáveis instrumentais (IV $)^{15}$, entretanto, como mostram Baum, Schaffer e Stillman (2003, 2007), na presença de heterocedasticidade, o GMM mostra-se mais adequado.

Portanto, para auxiliar na seleção do melhor método para a estimação dos modelos aqui utilizados, inicialmente, procede-se à aplicação do teste de heteroce-

\footnotetext{
${ }^{15}$ Vale ressaltar que, apesar de se mostrar consistente na presença de heterocedasticidade, o Estimador de GMM possui fraco desempenho em pequenas amostras. Portanto, quando o problema de heteros cedasticidade não está presente, é preferível ainda o emprego do estimador de variáveis instrumentais (Baum, Schaffer e Stillman, 2003, 2007).
} 
dasticidade de Pagan e Hall (1983) ${ }^{16}$ na estimação por variáveis instrumentais (IV). Adicionalmente, aplica-se também o teste de autocorrelação serial de Cumby e Huizinga (1992), que tem ausência de autocorrelação como hipótese nula. Assim, como destacado anteriormente, caso se rejeite a hipótese nula de homocedasticidade no teste Pagan e Hall (1983), utiliza-se a estimação de GMM com correção para este problema e, ainda, caso se verifique a presença de autocorrelação serial, aplica-se o chamado GMM-HAC, que é um estimador de GMM consistente na presença de heterocedasticidade e autocorrelação.

Em todos os casos analisados neste estudo, detectou-se a presença de heterocedasticidade e, portanto, utilizou-se o método dos momentos generalizados em todos os modelos estimados. Hansen (1982) mostra que, se os instrumentos são válidos, ou seja, correlacionados com os regressores endógenos e não correlacionados com o termo do erro, os estimadores de GMM são consistentes e assintoticamente normais. Portanto, utiliza-se o teste de sobreidentificação de Hansen (1982), que faz uso da hipótese nula de que os instrumentos são válidos. No caso de não rejeição da hipótese nula, diz-se que os instrumentos são válidos e que o modelo está estimado adequadamente.

Portanto, para a estimação GMM deste exercício empírico, os instrumentos ${ }^{17}$ incluem até seis defasagens da inflação, hiato do produto, custo marginal das empresas, hiato do desemprego e taxa de juros, nos moldes de Galí e Gertler (1999).

Assim, como visto na segunda seção, o modelo a ser estimado neste trabalho e sua condição de ortogonalidade na estimação por GMM são apresentados nas equações (13) e (14), respectivamente.

$$
\begin{aligned}
& \pi_{t}=\lambda c m_{t}+\gamma_{f} E_{t}\left\{\pi_{t+1}\right\}+\gamma_{b} \pi_{t-1}+\theta v_{t} \\
& E_{t}\left\{\left(\pi_{t}-\lambda c m_{t}-\gamma_{f} \pi_{t+1}-\gamma_{b} \pi_{t-1}-\theta v_{t}\right) z_{t}\right\}=0
\end{aligned}
$$

Em resumo, a estratégia econométrica para a estimação dos modelos utilizados neste estudo consiste inicialmente na investigação da presença de heterocedasticidade e autocorrelação serial na estimação IV através dos testes de Pagan e Hall (1983) e Cumby e Huizinga (1992), respectivamente ${ }^{18}$. Rejeitando-se a $H_{0}$ de homocedasticidade, utiliza-se o GMM com correção para este problema; caso se ve-

\footnotetext{
${ }^{16} \mathrm{Um}$ teste indicado para a estimação na presença de regressores endógenos. Tem homocedasticidade como hipótese nula.

${ }^{17}$ Além de serem tradicionalmente empregadas para estimar a CPNKH na literatura, o uso dessas variáveis em termos de suas defasagens reflete o caráter predeterminado desses indicadores em modelos de expectativas racionais e reforçam a ausência de correlação com variável a ser instrumentalizada. Adicionalmente, empregar-se-á o teste de Hansen de validade dos instrumentos para atestar a qualidade destes.

${ }^{18}$ Se os erros forem homocedásticos, Baum, Schaffer e Stillman $(2003,2007)$ mostram que o emprego do estimador de variáveis instrumentais é preferível, em virtude do fraco desempenho do GMM em pequenas amostras.
} 
rifique também a presença de autocorrelação serial, aplica-se a correção para ambos os problemas; ou seja, o GMM-HAC. Por fim, analisa-se o teste de Hansen (1982) de validade dos instrumentos e, caso não se rejeite $H_{0}$, diz-se que os instrumentos são válidos e que, portanto, o modelo está estimado adequadamente.

\section{ANÁLISE E DISCUSSÃO DOS RESULTADOS}

Para examinar o comportamento dinâmico da inflação brasileira considerando ambientes distintos de expectativas forward-looking na CPNKH utilizou-se o método GMM-HAC e informações mensais entre janeiro de 2002 e agosto de 2015.

Dessa forma, têm-se duas situações de expectativas; quais sejam, previsão perfeita (ou expectativas racionais) - onde se utiliza o próprio IPCA adiantado como expectativas forward-looking - e previsão sob incerteza (ou expectativas declaradas) - onde se utilizam três medidas extraídas do relatório Focus do Bacen, quais sejam, previsão Focus Mediana, previsão Focus $1^{\circ}$ dia e Focus Média. Além disso, em cada ambiente de expectativas, consideram-se três variáveis distintas para ciclos econômicos; quais sejam, custo marginal real das firmas, hiato do produto e o hiato do desemprego. Portanto, têm-se três modelos para cada ambiente de expectativas forward-looking, totalizando doze modelos estimados.

As Tabelas 2 e 3 sintetizam os resultados para os modelos estimados sob expectativas forward-looking previsão perfeita e expectativas declaradas, respectivamente. Inicialmente, seguindo a estratégia econométrica descrita anteriormente, observa-se que o teste de Pagan e Hall (1983) indicou a presença de heterocedasticidade em todos os modelos na estimação por variáveis instrumentais e, portanto, optou-se pelo uso do GMM em todas os casos. Além disso, o exame do teste de Hansen (1982) revela que não se pode rejeitar a hipótese nula de validade dos instrumentos em todos os modelos estimados, como se observa nas Tabelas 2 e 3 . Portanto, sob essas condições, pode-se afirmar que os modelos se encontram adequadamente estimados.

A Tabela 2 apresenta o resultado da estimação da CPNKH sob a hipótese de previsão perfeita, ou expectativas racionais. Vale ressaltar que os resultados do teste de autocorrelação de Cumby e Huizinga (1992) para todos os modelos indica a presença de autocorrelação e, portanto, fez-se uso do GMM com correção para heterocedasticidade e autocorrelação (GMM-HAC).

Em termos gerais, observa-se que apenas o hiato do produto não se mostrou estatisticamente significante a $5 \%$ e que os coeficientes estimados do impacto das expectativas backward-looking (ou inércia inflacionária), $\gamma_{b}$, se mostraram superiores aos das expectativas forward-looking, $\gamma_{f}$, ou seja, o possível aumento recente do grau de indexação da economia brasileira pode estar influenciando esse impacto, uma vez que autores que estimaram a CPNK para períodos anteriores observaram uma maior influência das expectativas forward-looking (Areosa e 
Medeiros, 2007; Correa e Minella, 2010; Mendonça, Sachida e Medrano, 2012). De fato, Simonsen (1970, 1985), Cabello (2014) e Carvalho (2014) advertem que um dos mecanismos de realimentação inflacionária é o aumento da indexação.

Analisando os impactos dos ciclos econômicos, $\lambda$, observa-se que o custo marginal das empresas apresentou impacto de 0,14 ; ou seja, majorando-se em 1 ponto percentual (p.p.) o custo marginal das empresas no mês, a inflação mensal aumentará em 0,14 p.p. Considerando um crescimento de 1 p.p. no desemprego cíclico, a inflação sofrerá um recuo da ordem de 0,32 p.p. Além disso, observou-se a presença de um repasse cambial, $\theta$, estatisticamente robusto variando de 0,003 p.p a 0,006 ao mês; ou seja, esse resultado pode indicar que as empresas que utilizam insumos importados em seu processo produtivo estão repassando parte desses custos para os preços para não experimentar prejuízo ou redução de seu markup, conforme argumentam Blonigen e Hayes (1999) e Gil-Pareja (2003). Essa evidência corrobora o resultado observado em Correa e Minella (2010) e Arruda, Ferreira e Castelar (2011).

Tabela 2: Estimativa GMM da Curva de Phillips Novo-Keynesiana Híbrida (Previsão Perfeita)

Expetativas Forward Looking: Previsão Perfeita

\begin{tabular}{|c|c|c|c|c|c|c|c|}
\hline \multirow{2}{*}{$\begin{array}{c}\text { Ciclos } \\
\text { Econômicos }\end{array}$} & \multicolumn{4}{|c|}{ Parâmetros } & \multirow{2}{*}{$\begin{array}{l}\text { Teste J } \\
\text { Hansen }\end{array}$} & \multirow{2}{*}{$\begin{array}{c}\text { Heterocedasticidade } \\
\text { Pagan } \\
\text { e Hall }\end{array}$} & \multirow{2}{*}{$\begin{array}{c}\text { Autocorrelação } \\
\text { Cumby } \\
\text { e Huizinga }\end{array}$} \\
\hline & $\lambda$ & $\gamma_{f}$ & $\gamma_{b}$ & $\theta$ & & & \\
\hline \multirow{2}{*}{$\begin{array}{l}\text { Custo } \\
\text { Marginal }\end{array}$} & 0,14 & 0,26 & 0,58 & 0,006 & 6,37 & $\chi^{2}(11)=19,88$ & $\chi^{2}(1)=11,85$ \\
\hline & $(0,00)$ & $(0,00)$ & $(0,00)$ & $(0,00)$ & $(0,49)$ & $(0,05)$ & $(0,00)$ \\
\hline \multirow{2}{*}{$\begin{array}{c}\text { Hiato do } \\
\text { Desemprego }\end{array}$} & $-0,32$ & 0,32 & 0,56 & 0,003 & 9,81 & $\chi^{2}(30)=51,91$ & $\chi^{2}(1)=20,92$ \\
\hline & $(0,00)$ & $(0,00)$ & $(0,00)$ & $(0,01)$ & $(0,77)$ & $(0,00)$ & $(0,00)$ \\
\hline \multirow{2}{*}{$\begin{array}{l}\text { Hiato do } \\
\text { Produto }\end{array}$} & $-0,42$ & 0,32 & 0,54 & 0,005 & 2,88 & $\chi^{2}(11)=20,06$ & $\chi^{2}(1)=6,9$ \\
\hline & $(0,28)$ & $(0,01)$ & $(0,00)$ & $(0,00)$ & $(0,71)$ & $(0,05)$ & $(0,00)$ \\
\hline
\end{tabular}

Fonte: Elaborado pelos autores com base na equação $\pi_{t}=\lambda x_{t}+\gamma_{f} E_{t}\left\{\pi_{t+1}\right\}+\gamma_{b} \pi_{t-1}+\theta v_{t}$. Nota: P-valor entre parênteses. Os testes de Autocorrelação e Heterocedasticidade foram aplicados na estimação com variáveis instrumentais. Todos os modelos foram estimados por GMM com correção para heterocedasticidade e autocorrelação (GMM-HAC).

Em seguida analisaram-se os modelos com variáveis de expectativas forward-looking com menor previsibilidade dos agentes econômicos, ou expectativas declaradas; quais sejam, previsão Focus Mediana, previsão Focus $1^{\circ}$ dia e Focus Média, respectivamente. Os resultados estão sintetizados na Tabela 3. Inicialmente, observa-se que o teste de autocorrelação de Cumby e Huizinga (1992) indicou a presença de autocorrelação apenas no modelo com expectativas forward-looking Focus $1^{\circ}$ dia com o custo marginal das empresas como 
variável de ciclos e, portanto, apenas esse modelo foi estimado por GMM corrigido tanto para autorrelação como para heterocedasticidade (GMM-HAC); para as demais regressões, empregou-se o GMM com correção apenas para heterocedasticidade. Apenas os coeficientes estimados do hiato do produto não apresentaram significância estatística.

Os resultados confirmam que os impactos do componente inercial, ou $b a$ ckward-looking, $\gamma_{b}$, da inflação brasileira recente se mostram superiores em magnitude aos das expectativas forward-looking em todos os modelos considerados; ou seja, além da previsão teórica do modelo de realimentação inflacionária de Simonsen $(1970,1985)$, estudos recentes como os de Cabello (2014) e Carvalho (2014) argumentam que o plano real não desindexou integralmente a economia brasileira e advertem para o aumento recente do grau de indexação no Brasil. Os coeficientes da inércia inflacionária variam de 0,52 a 0,69 , enquanto os das expectativas forward-looking estão entre 0,13 e 0,46; isto é, um incremento de 1 p.p. na inflação passada e na projeção futura majoram a inflação corrente entre 0,52 e 0,69 p.p. e entre 0,13 e 0,46 p.p., respectivamente.

Considerando os indicadores de ciclos econômicos, observa-se que, majorando-se em 1 p.p. o custo marginal das empresas, a inflação mensal aumentará entre 0,13 e 0,23 p.p.; todavia, se o aumento ocorrer no desemprego cíclico, a taxa de inflação se reduz entre 0,53 e 0,65 p.p. Por fim, observou-se que o indicador de repasse cambial também se mostrou significante do ponto de vista estatístico, com impactos positivos variando entre 0,003 e 0,006.

Tabela 3: Estimativa GMM da Curva de Phillips Novo-Keynesiana Híbrida (Expectativas Declaradas)

\begin{tabular}{|c|c|c|c|c|c|c|c|}
\hline \multicolumn{8}{|c|}{ Expetativas Forward-Looking: Previsão FOCUS (Mediana) } \\
\hline \multirow{2}{*}{$\begin{array}{c}\text { Ciclos } \\
\text { Econômicos }\end{array}$} & \multicolumn{4}{|c|}{ Parâmetros } & \multirow{2}{*}{$\begin{array}{l}\text { Teste J } \\
\text { Hansen }\end{array}$} & \multirow{2}{*}{$\begin{array}{c}\text { Heterocedasticidade } \\
\text { Pagan } \\
\text { e Hall }\end{array}$} & \multirow{2}{*}{$\begin{array}{c}\text { Autocorrelação } \\
\text { Cumby } \\
\text { e Huizinga }\end{array}$} \\
\hline & $\lambda$ & $\gamma_{f}$ & $\gamma_{b}$ & $\theta$ & & & \\
\hline \multirow{2}{*}{$\begin{array}{l}\text { Custo } \\
\text { Marginal }\end{array}$} & 0,13 & 0,30 & 0,55 & 0,004 & 10,02 & $\chi^{2}(21)=30,58$ & $\chi^{2}(1)=1,03$ \\
\hline & $(0,00)$ & $(0,00)$ & $(0,00)$ & $(0,03)$ & $(0,90)$ & $(0,08)^{* *}$ & $(0,31)^{*}$ \\
\hline \multirow{2}{*}{$\begin{array}{c}\text { Hiato do } \\
\text { Desemprego }\end{array}$} & $-0,65$ & 0,23 & 0,60 & 0,003 & 8,69 & $\chi^{2}(14)=27,99$ & $\chi^{2}(1)=0,001$ \\
\hline & $(0,00)$ & $(0,00)$ & $(0,00)$ & $(0,09)^{* *}$ & $(0,89)$ & $(0,08)^{* *}$ & $(0,97)^{*}$ \\
\hline \multirow{2}{*}{$\begin{array}{l}\text { Hiato do } \\
\text { Produto }\end{array}$} & $-0,09$ & 0,13 & 0,65 & 0,006 & 4,52 & $\chi^{2}(19)=30,35$ & $\chi^{2}(11)=0,70$ \\
\hline & $(0,34)$ & $(0,08)^{* *}$ & $(0,00)$ & $(0,00)$ & $(0,71)$ & $(0,04)$ & $(0,40)^{*}$ \\
\hline
\end{tabular}


Expetativas Forward-Looking: Previsão FOCUS (1º Dia do Mês)

\begin{tabular}{|c|c|c|c|c|c|c|c|}
\hline \multirow{2}{*}{$\begin{array}{l}\text { Ciclos } \\
\text { Econômicos }\end{array}$} & \multicolumn{4}{|c|}{ Parâmetros } & \multirow{2}{*}{$\begin{array}{l}\text { Teste J } \\
\text { Hansen }\end{array}$} & \multirow{2}{*}{$\begin{array}{c}\text { Heterocedasticidade } \\
\text { Pagan } \\
\text { e Hall }\end{array}$} & \multirow{2}{*}{$\begin{array}{c}\text { Autocorrelação } \\
\text { Cumby } \\
\text { e Huizinga }\end{array}$} \\
\hline & $\lambda$ & $\gamma_{f}$ & $\gamma_{b}$ & $\theta$ & & & \\
\hline \multirow{2}{*}{$\begin{array}{l}\text { Custo } \\
\text { Marginal }\end{array}$} & 0,14 & 0,46 & 0,52 & 0,004 & 8,40 & $\chi^{2}(15)=27,07$ & $\chi^{2}(1)=3,52$ \\
\hline & $(0,00)$ & $(0,00)$ & $(0,00)$ & $(0,01)$ & $(0,67)$ & $(0,02)$ & $(0,05)$ \\
\hline \multirow{2}{*}{$\begin{array}{c}\text { Hiato do } \\
\text { Desemprego }\end{array}$} & $-0,53$ & 0,41 & 0,53 & 0,004 & 2,10 & $\chi^{2}(9)=17,66$ & $\chi^{2}(1)=0,67$ \\
\hline & $(0,00)$ & $(0,00)$ & $(0,00)$ & $(0,07)^{* *}$ & $(0,83)$ & $(0,04)$ & $(0,41)^{*}$ \\
\hline \multirow{2}{*}{$\begin{array}{l}\text { Hiato do } \\
\text { Produto }\end{array}$} & $-0,01$ & 0,42 & 0,54 & 0,005 & 9,72 & $\chi^{2}(15)=24,92$ & $\chi^{2}(11)=2,33$ \\
\hline & $(0,95)$ & $(0,00)$ & $(0,00)$ & $(0,01)$ & $(0,55)$ & $(0,05)$ & $(0,12)^{*}$ \\
\hline
\end{tabular}

Expetativas Forward-Looking: Previsão FOCUS (Média)

\begin{tabular}{|c|c|c|c|c|c|c|c|}
\hline \multirow{2}{*}{$\begin{array}{c}\text { Ciclos } \\
\text { Econômicos }\end{array}$} & \multicolumn{4}{|c|}{ Parâmetros } & \multirow{2}{*}{$\begin{array}{l}\text { Teste J } \\
\text { Hansen }\end{array}$} & \multirow{2}{*}{$\begin{array}{c}\text { Heterocedasticidade } \\
\text { Pagan } \\
\text { e Hall }\end{array}$} & \multirow{2}{*}{$\begin{array}{c}\text { Autocorrelação } \\
\text { Cumby } \\
\text { e Huizinga }\end{array}$} \\
\hline & $\lambda$ & $\gamma_{f}$ & $\gamma_{b}$ & $\theta$ & & & \\
\hline \multirow{2}{*}{$\begin{array}{l}\text { Custo } \\
\text { Marginal }\end{array}$} & 0,23 & 0,29 & 0,60 & 0,006 & 8,07 & $\chi^{2}(18)=35,70$ & $\chi^{2}(1)=1,64$ \\
\hline & $(0,00)$ & $(0,01)$ & $(0,00)$ & $(0,00)$ & $(0,88)$ & $(0,00)$ & $(0,19)^{*}$ \\
\hline \multirow{2}{*}{$\begin{array}{c}\text { Hiato do } \\
\text { Desemprego }\end{array}$} & $-0,58$ & 0,35 & 0,60 & 0,005 & 3,87 & $\chi^{2}(18)=31,86$ & $\chi^{2}(1)=0,71$ \\
\hline & $(0,00)$ & $(0,00)$ & $(0,00)$ & $(0,00)$ & $(0,83)$ & $(0,02)$ & $(0,39)^{*}$ \\
\hline \multirow{2}{*}{$\begin{array}{l}\text { Hiato do } \\
\text { Produto }\end{array}$} & 0,06 & 0,17 & 0,69 & 0,003 & 11,35 & $\chi^{2}(24)=50,19$ & $\chi^{2}(1)=1,22$ \\
\hline & $(0,72)$ & $(0,01)$ & $(0,00)$ & $(0,08)^{* *}$ & $(0,93)$ & $(0,00)$ & $(0,26)^{*}$ \\
\hline
\end{tabular}

Fonte: Elaborado pelos autores com base na equação $\pi_{t}=\lambda x_{t}+\gamma_{f} E_{t}\left\{\pi_{t+1}\right\}+\gamma_{b} \pi_{t-1}+\theta v_{t}$. Nota: P-valor entre parênteses. Os testes de Autocorrelação e Heterocedasticidade foram aplicados na estimação com variáveis instrumentais. ${ }^{*}$ Modelo estimado por GMM com correção apenas para a heterocedasticidade. ${ }^{*}$ Estatisticamente significante a $10 \%$.

Em suma, pode-se afirmar que a CPNKH se mostrou um mecanismo robusto para explicar a dinâmica recente da inflação brasileira, uma vez que tanto o repasse cambial como as variáveis de ciclos econômicos, medidas pelo custo marginal real das empresas e pelo hiato do desemprego, se mostraram estatisticamente robustas e com os sinais previstos pela teoria. Além disso, as evidências também apontam para a significância estatística dos componentes de expectativas backward-looking e forward-looking e que o impacto do primeiro é maior, sugerindo que a dinâmica recente da inflação brasileira ainda possui um forte componente inercial. Essa evidência fortalece o indício de uma forte memória inflacionária no Brasil e, ainda, como argumenta Carvalho (2014), pode ser resultado do aumento recente da indexação da economia brasileira; ou seja, o autor argumenta que o 
Plano Real não desindexou a economia por completo, mas apenas reduziu a velocidade dos reajustes e, ainda, que o aumento do poder de barganha dos trabalhadores em anos recentes no Brasil pode ter potencializado o efeito da indexação sobre o repasse inercial para a inflação.

Apesar disso, o efeito do hiato do produto se mostra estatisticamente igual a zero em todos os modelos estimados. Este resultado confirma a evidência destacada na literatura nacional por Mazali e Divino (2010), Mendonça, Sachsida e Medrano (2012) e Sachsida (2013), e a literatura internacional, como Galí e Gertler (1999), Galí, Gertler e Lopez-Salido (2001) e Mankiw (2001), a qual corrobora a dificuldade desse indicador, como medida de ciclo econômico, para explicar a dinâmica da inflação.

Por fim, procedeu-se a uma análise comparativa das médias dos coeficientes estimados no modelo com previsão perfeita em relação à média dos seus pares estimados em ambientes de menor previsibilidade dos agentes econômicos. Os resultados estão sintetizados na Tabela 4.

Tabela 4: Comparação dos valores médios dos coeficientes estimados

\begin{tabular}{|c|c|c|c|c|c|}
\hline \multirow{2}{*}{\multicolumn{2}{|c|}{ Ciclos Econômicos }} & \multicolumn{4}{|c|}{ Valor Médio dos Coeficientes Estimados } \\
\hline & & \multirow{2}{*}{$\frac{\lambda}{0,14}$} & \multirow{2}{*}{$\frac{\gamma_{f}}{0,26}$} & \multirow{2}{*}{$\frac{\gamma_{b}}{0,58}$} & \multirow{2}{*}{$\begin{array}{c}\theta \\
0,006\end{array}$} \\
\hline \multirow{4}{*}{ Previsão Perfeita } & Custo Marginal & & & & \\
\hline & $\begin{array}{c}\text { Hiato do } \\
\text { Desemprego }\end{array}$ & $-0,32$ & 0,32 & 0,56 & 0,003 \\
\hline & Hiato do Produto & - & 0,32 & 0,54 & 0,005 \\
\hline & Média & - & 0,30 & 0,56 & 0,005 \\
\hline \multirow{4}{*}{$\begin{array}{c}\text { Expectativas } \\
\text { Declaradas } \\
\text { (Menor Previsibilidade } \\
\text { dos Agentes) }\end{array}$} & Custo Marginal & 0,17 & 0,35 & 0,56 & 0,005 \\
\hline & $\begin{array}{c}\text { Hiato do } \\
\text { Desemprego }\end{array}$ & $-0,59$ & 0,33 & 0,58 & 0,004 \\
\hline & Hiato do Produto & - & 0,24 & 0,63 & 0,005 \\
\hline & Média & - & 0,31 & 0,59 & 0,005 \\
\hline
\end{tabular}

Fonte: Elaboração própria. Os coeficientes do hiato do produto não foram considerados por serem estatisticamente iguais a zero.

Os resultados parecem indicar que, num ambiente de menor previsibilidade dos agentes, a inflação se mostra mais vulnerável às oscilações cíclicas da atividade econômica, $\lambda$, uma vez que o impacto dessas variáveis se mostra maior, em valor absoluto, quando consideramos as previsões Focus (média, mediana e $1^{\circ}$ dia) como variável de expectativa forward-looking. De fato, como argumentam Mendonça (2002, 2004) e Sicsú (2002), quanto mais crível for a autoridade monetária, maior será o poder preditivo dos agentes econômicos e, portanto, menor será o custo de desinflação em termos de variações dos ciclos da atividade econômica. E, ainda, considerando a média dos coeficientes estimados, observa-se também que no am- 
biente de menor previsibilidade, a dinâmica inflacionária parece ter o seu componente inercial majorado. Não se observam diferenças entre os coeficientes estimados do repasse cambial.

\section{CONSIDERAÇÕES FINAIS}

O presente trabalho analisou a dinâmica recente da inflação brasileira considerando ambientes distintos de expectativas forward-looking na CPNKH utilizando informações mensais entre janeiro de 2002 e agosto de 2015 e o método GMM-HAC.

Em termos gerais, os resultados confirmaram a inadequação do hiato do produto e a robustez do hiato do desemprego e do custo marginal das empresas como mecanismos para captar o repasse dos ciclos econômicos para a inflação do Brasil no período analisado. Ou seja, a medida de custo marginal real das empresas empregada neste estudo se mostra uma alternativa para aplicações futuras no Brasil. Além disso, observou-se um repasse cambial para a inflação positivo e estatisticamente significante.

As evidências também indicam a relevância das expectativas backward-looking e forward-looking e que o impacto da primeira é superior em todos os modelos analisados, indicando que a dinâmica inflacionária brasileira ainda possui um importante componente inercial. Carvalho (2014) argumenta que, embora o Plano Real tenha reduzido a velocidade dos reajustes, não desindexou plenamente a economia, e que, em anos recentes, houve uma acentuação do grau de indexação da economia, o que pode ter majorado o impacto do repasse inercial para a inflação. Assim, pode-se dizer que a CPNKH se mostra um arcabouço adequado para a investigação da dinâmica recente da inflação brasileira.

Os resultados sugerem, ainda, que a inflação se mostra mais sensível às oscilações nos ciclos econômicos quanto maior o grau de incerteza em relação às expectativas forward-looking; ou seja, num cenário de menor previsibilidade dos agentes. Portanto, quanto maior o poder preditivo dos agentes econômicos, o que sinaliza para uma maior credibilidade da autoridade monetária (Sicsú, 2002; Mendonça, 2002, 2004), menor será o custo de uma política de desinflação em termos de oscilações cíclicas na atividade econômica.

Em suma, com os resultados obtidos pode-se concluir que o aumento recente do grau de indexação da economia brasileira pode ter potencializado o repasse inercial para a inflação e que, quanto maior a previsibilidade dos agentes econômicos, menos onerosas serão as políticas de desinflação em termos de variações nos ciclos econômicos.

\section{REFERÊNCIAS BIBLIOGRÁFICAS}

Areosa, W. D. \& Medeiros, M. (20070 “Inflation dynamics in Brazil: The case of a small open economy". Brazilian Review of Econometrics, v. 27, p. 131-166. 
Arruda, E. F.; Ferreira, R. T \& Castelar, I. (2011) “Modelos lineares e não lineares da Curva de Phillips para a previsão da taxa de inflação no Brasil”. Revista Brasileira de Economia, v. 65, n. 3, p. 237 252.

Barro, R. J. \& Gordon, D. B. (1983) "Rules, discretion and reputation in a model of monetary policy". Journal of Monetary Economics, v. 12, p. 101-121.

Baum, C. F.; Schaeffer, M. E. \& Stillman, S. (2007) "Enhanced routines for instrumental variables/GMM estimation and testing”. Stata Journal, v. 7, ed. 4, p. 465-506.

Baum, C. F.; Schaeffer, M. E. \& Stillman, S. (2003) "Instrumental variables and GMM: Estimation and testing”. Stata Journal, v. 3, p. 1-31.

Blonigen, B. A. \& S. E. Hayes. (2002) "Antidumping investigations and the pass-through of antidumping duties and exchange rates". The American Economic Review, V. 92, No. 4, p. 1044-1061.

Cabello, A. F. ( 2014) "Mário Henrique Simonsen e a construção do conceito de inflação inercial". Revista de Economia Política, vol 34, n 2, p. 317-326.

Calvo, G.A. ( 1983) "Staggered prices in a utility-maximizing framework". Journal of Monetary Economics, v.12, n. 3, p. 383-98.

Carvalho, A. R. (2014) “A persistência da indexação no Brasil pós-Real”. Revista de Economia Política, v. $34, n^{\circ} 2$, p. $266-283$.

Correa, A. S. \& Minella, A. (2010) "Nonlinear mechanisms of the exchange rate pass-through: A Phillips Curve model with threshold for Brazil.” Revista Brasileira de Economia, v. 64, n. 3, p. 231-243.

Cumby, R. E. \& Huizinga, J. (1992) “Testing the autocorrelation structure of disturbances in ordinary least squares and instrumental variables regressions”. Econometrica, v. 60, nº 1, p. 185-195.

Fasolo, A. M.; Portugal, M. S. (2004) "Imperfect rationality and inflationary inertia: a new estimation of the Phillips Curve for Brazil. Estudos Econômicos, v. 34, n 4, p. 725-776, outubro - dezembro.

Friedman, M. (1968) “The role of monetary policy." American Economic Review, v. 58, p. 1-17.

Friedman, M. (1977) Inflation and unemployment: Nobel lecture". Journal of Political Economy, v. 85.

Galí, J. \& Gertler, M. (1999) "Inflation dynamics: a structural econometric analysis". Journal of Monetary Economics, v. 44, $\mathrm{n}^{\circ}$ 2, p. 195- 222.

Galí, J.; Gertler, M. \& Lopez-Salido, J. D. (2001) “European inflation dynamics.” European Economic Review, v. 45, n⿳0 7, p. 1237-1270.

Gil-Pareja, S. (2003) "Pricing to market behavior in European car markets", European Economic Review, v. $47, \mathrm{n}^{\circ} 6$, p. $945-962$.

Hansen, L.P. (1982) "Large sample properties of generalized method of moments estimator". Econometrica, v. 50, $\mathrm{n}^{\circ} 4$, p. $1029-1054$.

Hodrick, R. J. \& Prescott, E. C. (1997) "Post-war US business cycles: an empirical investigation”. Journal of Money, Credit, and Banking, v. 29, p.1-16.

Kydland, F. E. \& Prescott, E. C. (1977) "Rules rather than discretion: the inconsistency of optimal plans". The Journal of Political Economy, v. 85, p. 473-492.

Lima, E. C. R. (2003) “The NAIRU, unemployment and the rate of inflation in Brazil". Revista Brasileira de Economia, v. 57, n 4, p. 899-930.

Lucas, R. E. (1972) "Expectations and the neutrality of money". Journal of Economic Theory, v. 4, n. 2, p. 103-124.

Mankiw, N. G. (2001). The inexorable and mysterious tradeoff between inflation and unemployment. Economic Journal, 111:C45-C61.

Mazali, A. A. \& Divino, J. A. (2010) "Real wage rigidity and the New Phillips curve: The Brazilian case”. Revista Brasileira de Economia, v. 64, nº 3, p. 291-306.

Mendonça, H. F. (2002) “A teoria da credibilidade da política monetária. Revista de Economia Política, v. $22, n^{\circ} 3$, p. $46-64$.

Mendonça, H. F. (2004) “Mensurando a credibilidade do regime de metas inflacionárias no Brasil. Revista de Economia Política, v. 24, n 3, p. 344-350.

Mendonça, M. J. C.; Sachsida, A. \& Medrano, L. (2012) "Inflação versus desemprego: novas evidências para o Brasil”. Economia Aplicada, v. 16, p. 475-500.

Mendonça, H. F. \& Santos, M. A. L. dos (2006) “Credibilidade da política monetária e a previsão do 
Trade-off entre inflação e desemprego: Uma aplicação para o Brasil. Revista Economia, v. 7, p. 293-306.

Minella, A.; Freitas, P. S.; Goldfajn, I.; Muinhos, M. F. (2003) "Inflation targeting in Brazil: constructing credibility under exchange rate volatility". Journal of International Money and Finance, v. 22, $\mathrm{n}^{\circ}$ 7, p. 1015-1040.

Muth, J. F. (1961) Rational expectations and the theory of price movements”. Econometrica, v. 29, p. $315-335$.

Muinhos, M. K. (2004) "Inflation targeting in an open financially integrated emerging economy: the case of Brazil”. Estudos Econômicos, v. 34, n 2, p. 269-296.

Pagan, A. R. \& Hall, D. (1983) "Diagnostic Tests as Residual Analysis. Econometric Reviews. v. 2, n" 2, p. 159-218, 1983.

Phelps, E. S. Phillips Curve Expectation of Inflation and Optimum Unemployment Over Time. Economica, v. 34, p. 254-81, 1967.

Phelps, E. S. The New Microeconomic in Inflation and Employment Theory. American Economic Review, v. 59 , p. $147-160,1969$.

Phillips, A. W. The Relationship between Unemployment and the Rate Of Change Of Money Wages in the United Kingdom 1861-1957. Economica, v. 25(100), p. 283-299, 1958.

Phillips, P. \& Perron, P. Testing for a Unit Root in Time Series Regression. Biometrika, v. 75, p. 335-346, 1988.

Portugal, M. S.; Madalozzo, R. C. Um Modelo de Nairu Para o Brasil. Revista de Economia Política, v. $20, \mathrm{n}^{\circ} 4$, p. $26-47,2000$.

Portugal, M. S.; Madalozzo, R. C.; Hilllbrecht, R. O. Inflation, unemployment and monetary policy in Brazil. Encontro Brasileiro de Econometria - SBE, 1999.

Rudd, J. \& Whelan, K. New tests of the new Keynesian Phillips Curve. Journal of Monetary Economics, v. 52 , p. $1167-1181,2005$.

Sachsida, A. (2013) "Inflação, desemprego e choques cambiais: uma revisão da literatura sobre a Curva de Phillips no Brasil”. Revista Brasileira de Economia, v. 67, n. 4, p. 549-559.

Sachsida, A., Ribeiro, M., \& dos Santos, C. H. (2009) "A Curva de Phillips e a experiência brasileira". Texto para discussão, IPEA, 2009.

Sargan, J. (1958) "The estimation of economic relationships using instrumental variables". Econometrica. v. $26, \mathrm{n}^{\circ} 3$, p. 393-415.

Sargent, T. J. (1971) "A note on the accelerationist controversy". Journal of Money, Credit and Banking, v. 3, n. 3, p. 721-25.

Schwartzman, F. (2006) "Estimativa de Curva de Phillips Para o Brasil com preços desagregados". Economia Aplicada, v. 10, n. 1, p. 137-15.

Sicsú, J. (2002) Expectativas Inflacionárias no Regime de Metas de Inflação: uma análise preliminar do caso brasileiro". Revista de Economia Aplicada, São Paulo, v. 6, n.4, p. 703-711.

Simonsen, M. H. (1970) Inflação: Gradualismo X Tratamento de Choque, Rio de Janeiro: APEC.

Simonsen, M. H. (1985) "Contratos salariais justapostos e política anti-inflacionária”. Revista de Econometria, vol. $5, \mathrm{n}^{\circ} 2$, p. 5-32.

Taylor, J. B. (1980) “Aggregate dynamics and staggered contracts”. Journal of Political Economy, v. 88, p. $1-23$.

Tombini, A. A.; Alves, S. A. L. (2006) “The recent Brazilian disinflation process and costs.” Central Bank of Brazil Working Paper Series, n. 109, June. 